\title{
The Efficacy of Antipsychotics in the treatment of Physical Aggressive behavior in Patients with Dementia in Nursing Homes
}

\author{
Nawzad $S^{1}$, Wiepke Cahn ${ }^{1}$ and Abdullah-Koolmees $\mathrm{H}^{* 2}$ \\ ${ }^{1}$ UMC Utrecht, Netherlands \\ ${ }^{2}$ Division Laboratories, Pharmacy and Biomedical Genetics, UMC Utrecht, Netherlands
}

Submission: February 13, 2020; Published: March 02, 2020

*Corresponding author: Abdullah-Koolmees H, Division Laboratories, Pharmacy and Biomedical Genetics, UMC Utrecht, Netherlands

\begin{abstract}
Patients with dementia often suffer from behavioral changes. A common behavioral change is acute physical aggressive behavior which is the most distressing change. This can lead to harm, which is especially problematic in nursing homes. Despite the serious safety concerns, antipsychotics are often prescribed to combat this problem. This article is aimed to review the evidence of the efficacy of utilizing antipsychotics in acutely treating physical aggressive behavior in patients with dementia in nursing homes. Therefore, a systematic literature search was performed. The results included a meta-analysis confirmed statistically significant reduction in physical aggression when risperidone was compared to placebo. On the other hand, a randomized controlled trial showed no change in physical aggressive behavior between quetiapine and placebo. More research is needed to fully investigate the benefits on physical aggressive behavior and safety concerns of all the antipsychotics in patients with dementia in nursing homes. .
\end{abstract}

Keywords: Dementia, Antipsychotics; Neuropsychiatric symptoms; Aggressive behavior and Cohen-Mansfield Agitation Inventory (CMAI) scale

\section{Introduction}

Patients with dementia often suffer from behavioral changes, referred to as neuropsychiatric symptoms (NPS) or behavioral and psychological symptoms of dementia (BPSD) [1]. Up to $90 \%$ of patients with dementia develop BPSD [2]. BPSD include uninhibited behavior, agitation, and aggression. BPSD are very distressing for patients. Acute physical aggression can even lead to self-harm and harm to others around them $[3,4]$. This is especially problematic in nursing homes and needs to be managed both diligently and expeditiously. Nonpharmacological interventions, which is first-line treatment, is not effective in managing these symptoms for every patient, their benefits are typically limited to milder severity of aggression. For many patients fail these interventions after initial success [4]. Therefore, a wide variety of pharmacotherapies are often prescribed off-label to combat this problem. There are currently no 'USA Food and Drug Administration' (FDA)approved medications indicated for the treatment of aggression in patients with dementia. The European union, however, has only approved the antipsychotic risperidone for the treatment of persistent aggression in patients with moderate to severe Alzheimer's dementia [5]. Thus, there are no medications on the market indicated to treat acute aggression in this patient population. Nevertheless, antipsychotics are often used for this indication. The FDA issued warnings in 2003 and 2005 regarding the use of antipsychotics in patients with dementia [2]. Post-marketing surveillance demonstrated serious adverse events associated with the use of antipsychotics, including increased mortality. Evidence form clinical trials demonstrated a 1.5 to 1.8 -fold increased mortality [6,7]. Despite these safety concerns, antipsychotics are still being widely prescribed offlabel. Recently, Zuidema et al. [4] published a practice guideline regarding the prescribing of antipsychotics to patients with dementia in nursing homes. This guideline is intended to further aid clinicians in the treatment process. However, it is not evidence-based. This article aims to review the evidence of the efficacy of utilizing antipsychotics in the acute treatment of non-psychotic-induced dementia-related physical aggressive behavior in patients with dementia in nursing homes.

\section{Objective}

To investigate the efficacy of antipsychotics in acutely treating physical aggressive behavior in patients with dementia in nursing homes. 


\section{Methods}

A systematic literature search was performed on October 29th, 2018 in the following databases: Pubmed, Cochrane, and Embase. The targeted search was built with a 'patient intervention comparison outcome' (PICO)-model based on the following question: what is the efficacy of antipsychotics for the treatment of acute non-psychotic-induced aggressive behavior in patients with dementia in nursing homes? The population included patients in nursing homes with different forms of dementia and non-psychotic-induced acute aggressive behavior. The intervention was comparing antipsychotic to placebo. The outcome was efficacy such as a change in manifestation of aggressive behavior or a change in the frequency of aggressive behavior. Therefore, the search included the synonyms of dementia, aggressive behavior, and antipsychotics found in $\mathrm{MESH} /$ Emtree terms, supplementary concept title, and abstract. The labels languages (English), species (humans), and text availability (full text) were also added to the search criteria (see Appendix 1 for exact search terms). All search results were first manually checked based on relevance by reading the title and the abstract. Article types other than observational studies or randomized clinical trials (RCTs) that compared antipsychotics with placebo or meta-analysis investigating the efficacy of antipsychotic drugs were excluded considering RCTs and meta-analysis of RCTs as the 'best evidence' in the study hierarchy of therapeutic trials [8]. Additionally, articles were excluded if patients with other disease states were included (e.g., schizophrenia, Parkinson's disease, psychosis, and bipolar disease), utilized interventions other than antipsychotics (e.g. antidepressants), and contained outcomes other than efficacy (e.g. results with only safety data). These remaining articles were screened by the first author on November 4 th by inclusion criteria and outcome results. Articles that included patients without the diagnosis of dementia according to the Diagnostic and Statistical Manual of Mental Disorders IV (DSM-IV) in nursing homes or articles that did not specifically address acute aggressive behavior and had no separate data on aggressive behavior were also excluded.

\section{Results}

Overall, the initial search yielded 248 articles. Only 104 articles remained after excluding article types other than observational studies or RCTs that compared antipsychotics with placebo or meta-analysis. After reading the titles and abstracts, 35 articles remained based on the patient's disease states, utilized interventions, and outcomes. These articles were further full text screened based on their inclusion criteria (i.e. patients with dementia in nursing homes) and reported outcomes (i.e. data on physical aggressive behavior), narrowing the search results down to five articles (Appendix 2). In total, only five articles evaluated acute non-psychotic-induced aggressive behavior in patients with dementia that were residing in nursing homes and being treated with antipsychotics. One of these articles was a meta-analysis [9] that contained three RCTs [10-12], which were already a part of the final search results and were therefore excluded.

Table S1: Summary of Trial Design of the study conducted by Meehan et al. [15].

\begin{tabular}{|c|c|c|c|}
\hline Objective & Patient selection & Trial design & Efficacy assessment \\
\hline $\begin{array}{c}\text { To investigate the efficacy of } \\
\text { intramuscular injection of } \\
\text { olanzapine in the treatment } \\
\text { of agitation associated with } \\
\text { dementia. }\end{array}$ & $\begin{array}{c}\text { Patients (age }>55 \mathrm{y} \text { ) were } \\
\text { hospitalized or nursing home } \\
\text { residents. They had diagnoses } \\
\text { of probable or possible AD, } \\
\text { vascular dementia or both (mixed } \\
\text { dementia) according to DSM-IV or } \\
\text { NINCDS/ADRDA and documented } \\
\text { clinical symptoms of agitation. }\end{array}$ & $\begin{array}{c}\text { A randomized, multicenter, } \\
\text { double-blind, placebo-controlled } \\
\text { parallel study. Study Period began } \\
\text { with initiation of preliminary } \\
\text { evaluations for the first injection } \\
\text { and continued for 24h. }\end{array}$ & $\begin{array}{c}\text { aggression score from the first } \\
\text { dose to } 2 \mathrm{~h} \text {, and } 24 \mathrm{~h} \text { post first } \\
\text { injection. }\end{array}$ \\
\end{tabular}

Abbreviations: AD: Alzheimer's disease, BPSD: behavioral and psychological symptoms of dementia CMAl: Cohen-Mansfield agitation inventory. DSM-IV: Diagnostic and Statistical Manual of Mental Disorders IV, NINCDS/ADRDA: National Institute of Neurological and Communicative Disorders and Stroke/the Alzheimer's Disease and Related Disorders Association.

Table S2: Results of the total Cohen-Mansfield agitation inventory (CMAI) score.

\begin{tabular}{|c|c|c|c|c|c|}
\hline & \multicolumn{2}{|c|}{ Intervention } & Placebo & & Overall p-value \\
\hline $\begin{array}{l}\text { Intervention, mean } \\
\text { dose }\end{array}$ & $\mathrm{N}$ & Mean (SD) & $\mathrm{N}$ & Mean (SD) & \multirow{2}{*}{$>0.05$} \\
\hline Olanzapine, $2.5 \mathrm{mg} \mathrm{IM}$ & 71 & $\begin{array}{c}-3.8(2.9)^{*} \text { and }-2.8 \\
(3.2)^{* *}\end{array}$ & \multirow{2}{*}{67} & \multirow{2}{*}{$\begin{array}{c}-2.8(3.4) * \text { and }-2.2 \\
(3.6) * *\end{array}$} & \\
\hline Olanzapine, 5 mg IM & 66 & $\begin{array}{c}-4.0(3.9)^{*} \text { and }-3.4 \\
(3.9)^{* *}\end{array}$ & & & $<0.05^{*}$ and $>0.05^{* *}$ \\
\hline
\end{tabular}

Abbreviations: IM: Intramuscular Injection, SD: standard deviation. * Mean Change from Baseline at 2 Hours Post First Intramuscular Injection. ${ }^{* *}$ Mean Change from Baseline at 24 Hours Post First Intramuscular Injection.

Ultimately, there was one RCT and one meta-analysis analyzed in this study [9,13] see Tables $1 \& 2$ for relevant trial design and results. Their outcome, physical aggressive behavior, was assessed using the Cohen-Mansfield Agitation Inventory (CMAI) 
scale. CMAI is a frequency rating scale containing 29-items to asses various aggressive and agitated behaviors reported as the CMAI total score. The CMAI score can also be divided into subscale scores, such as verbal or physical aggression subscale score. The outcome in the studies was reported as the observed mean change in CMAI physical-aggression subscale score from baseline to endpoint $[9,14]$ The pooled data of the metaanalysis of Deyn et al. [9] demonstrated a statistically significant reduction in physical aggression when comparing risperidone to placebo. However, Zhong et al. [13] demonstrated no difference in mean change (from baseline to evaluated points) in CMAI physical aggression subscale score between quetiapine and placebo. (Table $1 \& 2$ )

\section{Discussion}

This systematic literature study shows that there is some evidence for the efficacy of risperidone in treating acute physical aggressive behavior in patients with dementia residing in nursing homes. However, quetiapine was not associated with statistically significant benefits, thus there is no evidence for the efficacy of quetiapine in treating acute physical aggressive behavior in patients with dementia in nursing homes. Other antipsychotics are not investigated to specifically treat non-psychosis-induced acute aggressive behavior in this specific patient population, namely patients with dementia residing in nursing homes. A double-blind study conducted by Meehan et al. [15] investigated the efficacy of rapid-acting intramuscular olanzapine in treating agitation associated with Alzheimer's disease and/or vascular dementia (Appendix 3). They concluded that olanzapine showed superiority to placebo on the CMAI score. A rapid acting intervention is precisely important in treating patient with acute physical aggressive behavior in nursing homes. However, this study did not report results on the psychical aggressive behavior subscale score separately and was therefore not included in this study. However, olanzapine may be promising to treat psychical aggressive behavior specifically in these patients who need acute treatment, although not all patients of this trail were nursing home residents. In addition, further research is needed to fully determine the efficacy of all the antipsychotic agents.

The strength of our study was the high level of evidence: results were obtained through a meta-analysis study and an RCT, all comparing antipsychotics to placebo. The meta-analysis conducted by De Deyn et al. [9] contained three RCTs, which were similar in design, patient characteristics, efficacy scale, intervention, and treatment duration. Therefore, pooling the data was justified and useful since a larger patient population allows more precise estimates of the effect size. Another strength was the specific research question and PICO. The population of this study was very specific: patients in nursing homes with different forms of dementia and non-psychotic-induced acute aggressive behavior. In order to investigate the efficacy of antipsychotics on change in manifestation of aggressive behavior or a change in the frequency of aggressive behavior, patients with psychosis were excluded. Furthermore, the outcome was likewise specific, being the CMAI physical-aggression subscale score. Articles that did not specifically address acute aggressive behavior and had no separate data on aggressive behavior were also excluded.

One limitation of the De Deyn et al. [9] study was their patient population. Their study included patients with psychosis (approximately 60\%), which was part of our exclusion criteria. However, they performed a subgroup analysis that showed significant improvement in aggressive behavior in patients that did not have psychosis. This ultimately indicates that risperidone may improve symptoms of aggression independent of its antipsychotic effect.

Currently, there is some evidence supporting the use of risperidone for treating acute physical aggressive behavior in patients with dementia residing in nursing homes. However, more research is needed on efficacy and safety. Thus, the recommendation for daily practice is to utilize risperidone when really necessary in this setting, despite its safety concerns, until we gain more insight into the safety and efficacy of utilizing these antipsychotics. The effect and safety should frequently be evaluated during treatment as antipsychotics can cause serious adverse events in elderly patients, including increased mortality $[6,7]$.

\section{Conclusion}

The objective of this study was to evaluate the efficacy of antipsychotic agents compared to placebo in treating acute physical aggressive behavior in patients with dementia residing in nursing homes. Results of the meta-analysis of De Deyn et al. [9] confirmed that risperidone might be an effective treatment for reducing physical aggressive behavior in this patient population. On the other hand, the randomized controlled trial of Zhong et al. [13] showed no change in physical aggressive behavior between quetiapine and placebo. Currently, only risperidone is proven to be effective in one meta-analysis for this indication and patient population. In conclusion, more research is needed to fully investigate the benefits of all the antipsychotics in treating acute physical aggressive behavior in patients with dementia residing in nursing homes. In the intermit, health care workers should prescribe antipsychotics reservedly and with extreme caution as a treatment for acute physical aggressive behavior in patients with dementia residing in nursing homes.

\section{References}

1. Porsteinsson AP, Antonsdottir IM (2017) An update on the advancements in the treatment of agitation in Alzheimer's disease. Expert Opin Pharmacother 18(6): 611-620.

2. Lin YT, Hwang TJ, Shan JC, Chiang HL, Sheu YH, et al. (2015) Dosage and duration of antipsychotic treatment in demented outpatients with agitation or psychosis. J Formos Med Assoc 114(2): 147-53.

3. Gilley DW, Whalen ME, Wilson RS, Bennett DA(1991) Hallucinations and associated factors in Alzheimer's disease. Journal of Neuropsychiatry 1991;3(4): 371-376. 
4. Zuidema SU, Johansson A, Selbaek G, Murray M, Burns A, et al. (2015) A consensus guideline for antipsychotic drug use for dementia in care homes. Bridging the gap between scientific evidence and clinical practice. Int Psychogeriatr 27(11): 1849-1859.

5. European Medicines Agency. Risperdal [Internet]. 2008 [cited 12 October 2018]. Available from.

6. Steinberg M, Lyketsos CG (2012) Atypical antipsychotic use in patients with dementia: managing safety concerns. Am J Psychiatry 169(9): 900-906.

7. Ballard C, Creese B, Corbett A, Aarsland D (2011) A typical antipsychotics for the treatment of behavioral and psychological symptoms in dementia, with a particular focus on longer term outcomes and mortality. Expert Opin Drug Saf 10(1): 35-43.

8. Sackett DL, Richardson WS, Rosenberg WM, et al., (1997) Evidence Based Medicine: How to practice and teach EBM. Churchill Livingstone, New York, USA.

9. De Deyn PP, Katz IR, Brodaty H, et al., (2005) Management of agitation, aggression, and psychosis associated with dementia: a pooled analysis including three randomized, placebo-controlled double-blind trials in nursing home residents treated with risperidone. Clin Neurol Neurosurg 107(6): 497-508.
10. Brodaty H, Ames D, Snowdon J, Woodward M, Kirwan J, et al., (2003) A randomized placebo-controlled trial of risperidone for the treatment of aggression, agitation, and psychosis of dementia. J Clin Psychiatry 64(2): 134-143.

11. De Deyn PP, Rabheru K, Rasmussen A, Bocksberger JP, Dautzenberg PL, et al., (1999) A randomized trial of risperidone, placebo, and haloperidol for behavioral symptoms of dementia. Neurology 53(5): 946-955.

12. Katz IR, Jeste DV, Mintzer JE, Clyde C, Napolitano J, et al., (1999) Comparison of risperidone and placebo for psychosis and behavioral disturbances associated with dementia: a randomized, double-blind trial. Risperidone Study Group. J Clin Psychiatry 60(2): 107-115.

13. Zhong KX, Tariot PN, Mintzer J, et al., (2007) Quetiapine to treat agitation in dementia: a randomized, double-blind, placebo-controlled study. Curr Alzheimer Res 4(1): 81-93.

14. Cohen-Mansfield J, Billig N (1986) Agitated behaviors in the elderly. I. A conceptual review. J Am Geriatr Soc 36(10): 711-721.

15. Meehan KM, Wang H, David SR, Nisivoccia JR, Jones B, et al., (2002) Comparison of rapidly acting intramuscular olanzapine, lorazepam, and placebo: a double-blind, randomized study in acutely agitated patients with dementia. Neuropsychopharmacology 26(4): 494-504.

Your next submission with Juniper Publishers will reach you the below assets

- Quality Editorial service

- Swift Peer Review

- Reprints availability

- E-prints Service

- Manuscript Podcast for convenient understanding

- Global attainment for your research

- Manuscript accessibility in different formats

(Pdf, E-pub, Full Text, Audio)

- Unceasing customer service

Track the below URL for one-step submission

https://juniperpublishers.com/online-submission.php 